\title{
A visibilidade da ciência nos selos postais comemorativos ${ }^{1}$
}

Diego Andres Salcedo e Isaltina Maria A. M. Gomes

\section{Resumo}

Este artigo trata da divulgação da ciência por meio das imagens impressas nos selos postais. A ciência faz parte cada vez mais da concepção de ser-no-mundo, tanto nos fatos quanto nos ditos e nos vistos. A imagem tem sido utilizada como um recurso discursivo que informa, comunica e interpela o indivíduo, modifica seu mundo e tem papel importante na construção da realidade social. 0 selo postal, do tipo comemorativo, pode ser considerado um meio de divulgação de informações científicas utilizado tanto para enviar mensagens ao grande público quanto para educar novos leitores de mundo. Tomando por base estudos sobre culturas visuais, procuramos identificar em um selo postal, a presença da ciência nos níveis textual e pictórico.

Palavras-chave

Cultura visual. Divulgação científica. Filatelia. Selo postal comemorativo.
Diego Andres Salcedo | w159444x@gmail.com

Mestrando no Programa de Pós-Graduação em Comunicação da Universidade Federal de Pernambuco - UFPE. Professor do Departamento de Ciência da Informação da UFPE.

Isaltina Maria A. M. Gomes | isaltina@gmail.com

Doutora em Linguística pela Universidade Federal de Pernambuco - UFPE. Professora do Departamento de Comunicação Social e Coordenadora da Pós-Graduação em Comunicação da UFPE.

\section{Introdução}

A estreita relação entre Ciência e Tecnologia

(binômio que resultou na abreviatura C\&T e utilizado no singular) é tema das agendas políticas e econômicas de todos os países. No Brasil, até 0 início do século XXI, essa relação ainda parece ser mal compreendida, estranha e distante do imaginário social.

Assim também pensa Izquierdo (2005, p. 114), quando afirma que "0 desinteresse e desconhecimento da população brasileira sobre a ciência e a tecnologia causa um empecilho para 0 seu desenvolvimento e redução de sua independência econômica". Izquierdo (2005, p. 114) acredita que existe uma forma de preconceito arraigada na sociedade brasileira: "0 Brasil conhece pouco sobre ciência porque há uma crença de que isto é 'coisa de primeiro mundo' e ignora-se a realizada no país".

Nas agendas mencionadas, a discussão sobre essas duas culturas considera em ampla medida a direta relação que os produtos científicos e tecnológicos têm com 0 desenvolvimento e 0 
progresso. A ampliação desse escopo temático encontra espaço nas instituições de pesquisa e nas escolas de pensamento. 0 debate sobre as concepções atuais das Ciências e das Tecnologias, por sua vez, ultrapassa os limites das instituições sociais, perpassa as mídias e encontra lugar nas distintas esferas sociais, sejam elas públicas ou privadas.

Identificar, descrever e analisar as semelhanças e diferenças entre as Ciências e Tecnologias, tanto com relação aos aspectos qualitativos como quantitativos, envolve inúmeras variáveis num processo histórico complexo e intricado. É um movimento no tempo-espaço de acordo com as condições de possibilidades de combinações dessas variáveis. As Ciências e as Tecnologias, não obstante essenciais, são apenas duas variáveis concernentes ao desenvolvimento e progresso.

0 fato de usarmos esses termos no plural é proposital e vai de encontro à noção singular de C\&T. Opõe-se à noção de uma Ciência e Tecnologia universal, preponderante e hegemônica. Ciência e Tecnologia são ramificações de ditos e não-ditos passados que tangenciam a superfície de um continuum histórico no mundo das ideias, no imaginário humano. Decerto, existem fios condutores que podem explicar conceitos como "Unidade Científica", "Campo Científico", "Disciplina Científica" ou "Inovação Tecnológica", mas isso não significa que se concebam como válidos para todos e em todos os lugares.

0 interesse sobre esse assunto pode ser explicado, de forma sucinta, pela convergência de múltiplos fatores. Numa primeira análise, percebe-se que tanto as Ciências como as Tecnologias estão culturalmente imbricadas no sistema capitalista mundializado. As práticas de produção, distribuição e consumo de bens e serviços, além dos modelos educacionais, são constantemente permeados por culturas tecno-científicas. Esse sistema interpreta os significados, as aplicações e o somatório de conhecimentos dessas culturas, além de apropriar-se delas para sua própria reprodução.

A rigor, a tecnologia não precisa ser nova ou complexa, mas, nas sociedades modernas, 0 termo vem ganhando conotação de algo novo e significativamente mais avançado, sob a forma de novos bens e processos de produção, distribuição e utilização (ROSENTHAL apud PINHEIR0; PINHEIRO, 2002, p. 157).

Outro fator se refere ao fato de que 0 sistema científico, em que coexistem as instituições que realizam e fomentam pesquisas, as comunidades científicas, o processo de comunicação científica e a prática de popularização e educação científica, encontra em suas partes as condições de flexibilidade, continuidade e aplicabilidade nos diversos e distintos setores sociais.

Um terceiro aspecto diria respeito à impossibilidade e à inadequação, apesar de 
não ser o foco deste trabalho, de analisar esses termos sem levar em consideração a sua correlação com noções econômicas, ecossistêmicas, éticas e históricas. Por exemplo, do ponto de vista histórico, seria concebível um estudo sobre os conceitos sistematizados por Aristóteles sobre Ciência (episteme) e Técnica (techné), revistos por Granger (1994), que representa um marco fundador do pensamento ocidental. Outro exemplo trataria da utilização da tecnologia no sistema capitalista sob duas perspectivas: a de Marx (apud KATZ, 1996) e a de Schumpeter (1998).

Sabe-se, no entanto, que as Ciências e as Tecnologias são variáveis dentro de um complexo sistêmico mais amplo, ramificadas na superfície não linear, descontínua e de rupturas histórico-revolucionárias. Em alguns períodos, as Ciências e as Tecnologias são identificadas como atividades humanas distintas e desconexas, em outros elas se tornam praticamente indissociáveis.

Antes, porém, é prudente sugerir algumas indagações que norteiam os estudos que vêm sendo realizados. Como é o relacionamento entre as Ciências, as Tecnologias e a Comunicação? Quais são os objetos que validam uma abordagem dessa tríade? Por quem, onde, quais e como as imagens das culturas tecno-científicas são criadas? Em que suportes de informação são registradas e disseminadas? Como criam correlações de legitimação com e sobre as pessoas? Até que ponto esse suportes (impressos e eletrônicos) servem como alicerce ao status quo das culturas tecno-científicas? Como lê-los? Como educar as futuras gerações para lidar com essas imagens? Essas indagações são pertinentes e não compactuam com a afirmação de Ellul $(1968$, p. 6), quando sugere que "[...] discutir as relações entre as Ciências e as Tecnologias seja um verdadeiro mata-burro".

\section{Cultura visual}

Vestígios imagéticos compõem o pretérito da humanidade, se situam no presente e prosseguirão no futuro. A imagem é, enfim, um meio de expressão da cultura humana. 0 estudo da imagem necessita uma trajetória interdiscilpinar e, também, uma atenção a sua fluidez no cotidiano.

Bessis (1994, p. 159) sugere que a palavra imagem vem do grego $($ mimos $=$ imitação e genes $=$ nascido de) "[...] nascida da imitação, transmite ao que vê tanto o conhecido como 0 desconhecido, ornando-os de um valor estético e significativo". Apela para a imaginação daquele que produz e interpela, aquele que vê 0 produto imagético.

A visão é a mais importante modalidade de percepção que os humanos dispõem para apreender e conhecer o mundo exterior, estabelecendo como uma poderosa fonte de informação e conhecimento. Santaella (1993, p. 11) afirma que "uma das explicações para a 
predominância da visão [...] sobre os outros sentidos é a ligação direta dos olhos [...] com 0 cérebro, o que faz com que parte da atividade que deveria ser realizada por ele é feita pelos próprios órgãos".

Ainda que trabalhar com conceitos seja uma atividade fluída e incerta, talvez até ininterrupta, é pertinente ampliar a visão sobre os conceitos de imagem. No campo da Neurologia, Damásio (2000, p. 24) afirma que "imagem designa um padrão mental em qualquer modalidade sensorial". Em outro momento de sua obra, 0 autor explica com maior detalhe sua concepção de imagem tomada como um sinônimo de representação.

\begin{abstract}
Refiro-me ao termo imagens como padrões mentais com uma estrutura construída com os sinais provenientes de cada uma das modalidades sensoriais - visual, auditiva, olfativa, gustatória e sômato-sensitiva. A [última] modalidade inclui várias formas de percepção: tato, temperatura, dor, [etc.]. A palavra imagem não se refere apenas a imagem 'visual' e, também não há nada de estático nas imagens...As imagens de todas as modalidades 'retratam' processos e entidades de todos os tipos, concretos e abstratos. As imagens também 'retratam' as propriedades físicas das entidades e, às vezes imprecisamente, às vezes não, as relações espaciais e temporais entre entidades, bem como as ações destas. Em suma, o processo que chegamos a conhecer como mente quando imagens mentais se tornam nossas, como resultado da consciência, é um fluxo contínuo de imagens, e muitas delas se revelam logicamente inter-relacionadas...Pensamento é uma palavra aceitável para denotar esse fluxo de imagens (DAMÁSIO, 2000, p. 402).
\end{abstract}

Partindo de afirmações como essa, Contrera e Baitello Jr. (2006, p. 117) vão sugerir dois aspectos pertinentes aos estudos das imagens no âmbito das teorias da Comunicação e das Mídias:

a) "0 fluxo de mão dupla existente entre a motivação interna e a captação externa, que se articula na criação das imagens com as quais pensamos". Aqui caberiam as discussões sobre Teoria da Imagem (psíquicas e oníricas), da Recepção e do Imaginário;

b) "As consequências (sócio-ecológicas e ecopsicológicas) do predomínio avassalador dos sistemas comunicativos em detrimento das outras modalidades perceptivas". Aqui é possível estudar de forma crítica sobre as "eras de exacerbação da visualidade, do simulacro e da iconofagia".

A imagem situa-se num contexto em que o sujeito gera, reproduz, decifra, enuncia, cria e re-lê, todavia sempre historicamente possibilitado.

Manguel (2003, p. 21) aponta para o fato de que

As imagens, assim como as histórias, nos informam [...] para aqueles que podem ver, a existência se passa em um rolo de imagens que se desdobra continuamente, imagens capturadas pela visão e realçadas ou moderadas pelos outros sentidos, imagens cujo significado (ou suposição de significado) varia constantemente, configurando uma linguagem feita de imagens traduzidas em palavras e de palavras traduzidas em imagens, por meio das quais tentamos abarcar e compreender nossa própria existência. As imagens que formam nosso mundo são símbolos, sinais, mensagens, alegorias. Ou talvez sejam apenas presenças vazias que completamos com o nosso desejo, experiência, questionamento e remorso. Qualquer seu seja 0 caso, as imagens, assim como as palavras, são a matéria de que somos feitos. 
A imagem pertence aos universos interior (endógeno) e exterior (exógeno) do ser humano. A sua forma de interpelar não deve remeter a uma suposta linearidade histórica, muito menos sugerir o mesmo com relação ao modo de leitura, mas a um emaranhado feixe de relações de poder e saber. A complexidade da tradução das representações visuais é complicada porque converge tanto à percepção da imagem quanto sua produção. Mas vai além, quando se entende que essa atividade também constitui um processo de aquisição de conhecimento ininterrupto através das experiências e dos afetos sociais, dos indivíduos e das coletividades. Assim explicam Santaella e Noth (2005, p.15):

0 mundo das imagens se divide em dois domínios. 0 primeiro é o domínio das imagens como representações visuais: desenhos, pinturas, gravuras, fotografias e as imagens cinematográficas, televisivas, holo e infográficas pertencem a esse domínio. Imagens, nesse sentido, são objetos materiais, signos que representam 0 nosso meio ambiente visual. 0 segundo é 0 domínio imaterial das imagens na nossa mente. Neste domínio, imagens aparecem como visões, fantasias, imaginações, esquemas, modelos ou, em geral, como representações mentais. Ambos os domínios da imagem não existem separados, pois estão inextricavelmente ligados já na sua gênese. Não há imagens como representações visuais que não tenham surgido de imagens na mente daqueles que as produziram, do mesmo modo que não há imagens mentais que não tenham alguma origem no mundo concreto dos objetos visuais.

Não se pode negar que, nos dias atuais, o sujeito tem refletido na imagem a sua complexidade, uma condição possível de seu estado. Essa complexidade é ambígua, multifacetada de significados e conceitos, que leva ao amanho da polissemia. Segundo Mafesoli (2001, p. 80), a "aceitação desse estado, não é, na realidade, senão o reconhecimento do aspecto complexo, polissêmico" do sujeito atual.

A imagem pensada num sentido social de fluxo e troca de informações entre sujeitos revela efeitos discursivos, possibilita conteúdos enunciativos, fomentados por ideologias, e sugere intenções. É uma intenção discursiva, no sentido sugerido por Bakhtin (2003), em que seria essa uma das maneiras de assegurar o todo enunciativo. $\mathrm{Na}$ correlação entre 0 que é visto e 0 é-não-visto, entre 0 que é dito e o é-não-dito jazem saberes, sensações, poderes, formas e desejos.

$\mathrm{Na}$ atualidade, existe uma avalanche de informações visuais que interpelam o Ser, 0 seduz, 0 educa e 0 individualiza, mas, ao mesmo tempo, 0 assujeita e gera sua desterritorialização. Decerto, o discurso visual pode ser analisado, na medida em que ali se busquem possíveis deslocamentos de sentidos e correlações entre os efeitos característicos de um certo momento histórico. Esse é o caso, também, das imagens impressas nos selos postais.

Pode-se tentar olhá-las para além de uma prática material, de uma técnica, que com certeza tem sua validade, como atesta Bronowski (1998, p. 89): "A fabricação de artefatos é um traço característico de todas as culturas humanas". Pode-se também entendê-las como um 
assemblage coletivo, ou seja, um lugar no tempoespaço onde estão imbricados poderes, saberes, historicidades, práticas discursivas e estéticas.

Desde tempos remotos, as civilizações leram e elaboraram imagens. 0 que pode ser interessante discutir é que a imagem, enquanto objeto de análise, revela distintas dimensões da experiência social, a multiplicidade de grupos humanos (grupos sociais) e seus modos de relacionamento.

A cultura visual fornece material que cria e transforma identidades pelas quais os indivíduos compartilham os ambientes sócio-históricos. 0 reconhecimento de que a produção de imagens é uma prática discursiva envolve diferentes enfoques que se identificam com várias tradições disciplinares. Analisar essa cultura visual permite a exploração de algumas das formas pelas quais as mídias reiteram as relações de poder, constroem e modificam identidades, verdades, grupos sociais e tecnologias. Todo esse emaranhado feixe de relações pressupõe o surgimento de um novo campo disciplinar, estudos visuais (ou culturas visuais), que tem como característica relevante a investigação interdisciplinar. Esse campo vai interrogar o papel ou a função de qualquer tipologia imagética, nas distintas culturas e sociedades. Mas não apenas isso.

Alguns autores que discorrem sobre os conceitos que residem nos estudos sobre Cultura Visual, no Ocidente, sugerem distintas tendências de investigação científica. São exemplos: Berger
(1972); Bryson, Holly e Moxey (1991; 1994);

Haskell (1993); Mitchell (1994); Bird (1996);

Jay (1996); Mirzoeff (1998); Evans e Hall

(1999); Elkins (2003); Dikovitskaya (2005);

Knauss (2006, p. 107). 0 momento atual amplia a discussão proposta no século XX e sugere maior complexidade sobre 0 assunto. Isso se dá, sobretudo, ao levar em conta 0 advento da midiatização das culturas atuais, no sentido de que há uma predominância da imagem em relação à hegemonia das formas linguísticas midiáticas mais antigas. A imagem, situada no centro do palco midiático, propõe uma situação panóptica.

A voga dos estudos de "cultura visual" assinala com clareza [...] aquilo que já foi chamado de pictorial turn, em sequência ao linguistic turn de décadas anteriores, que chamaram a atenção para o texto antropológico ou sociológico na produção de conhecimento (MENESES, 2003, p. 21).

0 que sugere essa nova realidade paradigmática é a proposição de novos rumos, novos métodos e novos riscos teóricos para o estudo das culturas visuais. 0 visual como discurso e 0 cultural como ente metamórfico. A cultura faz-se visível e, em contrapartida, o visível torna-se cultura. Mas há de se considerar, nesse co-relacionamento de metaobjetos visuais e culturais, construídos no existente agora, o seu processo histórico de tensão somado com os elementos do não-visível.

A partir desses estudos sobre as possíveis culturas visuais a proposta neste artigo é analisar o selo postal, do tipo comemorativo, como veiculador de informações científicas. Para tanto, 
a imagem será considerada enquanto objeto de estrutura significante, que viabiliza a construção de sentidos. Entendemos que a interface imagética irá possibilitar ao leitor a compreensão de que os códigos icônicos ali presentes apontam para a relevância das atividades científicas, suas conquistas, seus méritos e, por vezes, seus malefícios, e os atores e instituições sociais envolvidos nessa específica esfera das sociedades.

\section{0 selo postal comemorativo}

0 que dizer de tão rica e lúdica fonte de informação? Esse pequeno pedaço de papel, indiferente às diversas formas como se apresenta e aos suportes aos quais é agregado, elimina distâncias, preserva na forma de texto e imagem (relação verbo-viual), com criatividade, uma possível história da humanidade.

Para muitos, esses "pequenos embaixadores de papel" (SALCED0, 2006, p. 1) são vistos e tidos, de forma míope, como papel gomado ou não, ilustrado, todavia, insignificante. Ler o mundo no sentido de emancipar o intelecto é, com certeza, uma das maiores dificuldades do indivíduo deste século. Acreditamos que o selo postal, enquanto material ilustrativo, tem características marcantes, entre as quais, ser aproveitado tanto para enviar mensagens ao grande público como para educar novos leitores de mundo. Isso é possível porque sua estrutura física enquanto objeto material é de fácil manuseio. "Aos selos poder-se-ia aplicar a síntese feita por Abraham Moles para 0 cartaz. Eles têm a função de informar (qual a comemoração, o feito, o objeto da emissão) e de educar (dando a conhecer valores ou temas que escolheram)" (ERBOLATO, 1983, p. 115).

Os selos postais estão entre os produtos do Estado que possuem maior visibilidade interna e externa, assim como a moeda e outros símbolos iconográficos, os quais servem para legitimar uma nação. Altman (1991, p. 4) ratifica essa assertiva ao afirmar: "stamps have become useful ideological and cultural artifacts, and a means for governments to [...] promote certain images at home and abroad". Selos postais são produtos do Estado. Por meio de elementos verbo-visuais, relacionando texto e imagem, a nação/entidade emissora veicula tanto dentro de suas fronteiras como para além delas características de sua cultura visual.

De acordo com as especificações de texto e imagem impressas, 0 selo postal poderia, inclusive, ser considerado como um gênero midiático. Essa ideia é sustentada principalmente pelo fato de 0 alcance do selo postal ser bastante amplo. 0 selo postal encontra seu público nos mais variados ambientes: em correspondências particulares e corporativas; no comércio nacional e internacional; nas transferências bancárias, via correio; durante as guerras, tanto entre os combatentes como através das cartas beneficentes - Cruz Vermelha; nas campanhas religiosas; entre governos e suas embaixadas; nas agências internacionais 
que se comunicam através de documentos oficiais; no comércio filatélico; nas reuniões de colecionadores; nos anúncios e matérias escritos por jornalistas filatélicos; na própria internet, através do comércio eletrônico; em museus, arquivos e bibliotecas e, por fim, no dia-a-dia daquelas pessoas ou instituições que utilizam qualquer tipo de serviço postal, tanto do ponto de vista de quem envia como de quem recebe.

Além disso, a mensagem impressa no selo é intencional. "Os selos constituem um excelente meio de propaganda, e assim sendo, justo é que os governos se esforcem de representar fatos, episódios, e vultos do nosso país" (BOLETIM DA SOCIEDADE FILATÉLICA PAULISTA apud ALMEIDA; VASQUES, 2003, p. 96). Resgata, na forma de documento temático, as pessoas e seus feitos, efemérides, eventos, símbolos (locais, nacionais e internacionais), celebrações, costumes, tradições, processos e 0 tempo (memória), de forma particular e geral. Funciona como um elo entre os indivíduos e seu processo histórico.

No mundo inteiro, as emissões são disponibilizadas ao público em grande variedade de temas e, muitas vezes, com tiragens bastante expressivas. Por exemplo: para cada tema definido e selecionado, são emitidos em média 300.000 exemplares. Some-se a esse número uma média de 25 temas anuais, tem-se uma média de 7.500.000 selos postais emitidos anualmente. Esses números são distintos e inconstantes, se for levada em consideração a conjuntura políticoeconômica de cada país ou instituição emissora. 0 selo postal, enquanto documento, é constituído de elementos químicos (ex.: goma) e físicos (ex.: papel), formatos diversos, espaço reduzido, além de conteúdos múltiplos e correlacionados. Mas também é resultado de um processo técnico e de atos normativos que possibilitam seu surgimento. Em certa medida é possível afirmar que o selo postal é um artefato em que se imbricam, simultaneamente, arte e ciência. 0 selo postal tem uma função alicerçada na razão de seu surgimento, no século XIX, mas também tem "a função de informar e de educar" (ERBOLATO, 1983, p. 115). Salcedo (2008, p. 5) sugere que as informações "textuais e pictóricas" registradas nesses pequenos artefatos culturais constituem-se discursos de conteúdo endógeno e exógeno, que passam despercebidos ao leitor comum que apenas os identificam como taxas devidas ao correio para envio de missivas postais. Mas não é possível afirmar o mesmo sobre os ajuntadores, colecionadores, filatelistas e comerciantes filatélicos, além das instituições e organizações que, de uma forma ou de outra, tratam com esse objeto. Desde o advento do selo postal comemorativo, no final do século XIX, as administrações postais de vários países, que por sua vez são ligadas hierarquicamente ao poder executivo, monárquico ou republicano, começaram a imprimir nos selos postais mais do que cifras, efígies e brasões. 
A relação entre a criação, a produção, a

distribuição e o consumo da massa documental

filatélica ${ }^{2}$ tem uma história muito rica de

informações, não apenas no que concerne

ao documento em si, mas no que está ali

registrado, seu dizer, seu discurso. Desse

conjunto de documentos, o selo postal adesivo, do tipo comemorativo, tem características

verbo-visuias que transcendem a função administrativo-postal e por isso interpelam, para além das esferas do mercado filatélico, todos que com ele se deparam.

\section{Visibilidade da informação científica no selo postal comemorativo}

A compreensão das formas de comunicação do fazer ciência é condição inerente à formação de redes sociais e, simultaneamente, um desafio à própria ciência, pois se espera responsabilidade perante a sociedade. Um diagnóstico das estratégias de comunicação para o público leigo é essencial para a melhoria do processo. 0 resultado esperado é conferir maior visibilidade à ciência produzida no país, com o intuito de possibilitar a apropriação de conhecimento pelos diferentes sujeitos. Isso resultará num processo de retroalimentação dos fluxos de informação científica.

São inúmeras as alternativas possíveis para a divulgação da produção gerada pelos cientistas. Dependendo das que forem utilizadas, o conhecimento gerado será mais ou menos acessível à comunidade. Toda essa multiplicidade de documentação faz parte do sistema de comunicação científica, que compreende canais formais e informais utilizados pelos cientistas e pelas instituições, tanto para comunicarem os processos do fazer científico, como os resultados das pesquisas ao público leigo e também a outros pesquisadores. Nesse sistema, os cientistas são produtores e consumidores de informação científica.

0 conceito de visibilidade da ciência, independentemente do suporte ao qual sua imagem esteja vinculada, pode ser considerado um indicador para aferir o grau de exposição da ciência ou do fluxo de informação científica no âmbito da comunicação científica. Nesse sentido, as imagens de cientificidade contidas nos selos postais comemorativos brasileiros, emitidos no século XX, podem contribuir para, de algum modo, dar visibilidade à ciência.

Identificamos no Catálogo de Selos do Brasil (2008) 0 acervo brasileiro de selos postais comemorativos emitidos entre 1900 e 2000, com um total de 2354 peças. A partir daí, foi possível observar recorrências de elementos verbo-visuais de caráter científico e assim estabelecer uma classificação preliminar, a saber: 
1. Área científica

\section{Cientistas}

\section{Instituição científica}

4. Equipamento científico

5. Símbolo científico

6. Evento científico

0 resultado dessa classificação tipológica possibilitou a seleção de uma amostra com 847 selos postais comemorativos. Para além da classificação realizada, outros dois aspectos lhes são peculiares. Diferentemente de outros tipos de selos postais, eles têm sua tiragem e seu período de validade pré-determinados, além de que três elementos verbo-visuais devem ser, obrigatoriamente, impressos seguindo um padrão normativo internacional. Esses elementos são: 0 motivo de sua emissão, o valor facial e o nome do país ou instituição emissora. A seguir, um selo postal foi destacado da amostra para possibilitar a visualização do que foi explanado até o momento.

Os elementos que caracterizam essa peça como um selo comemorativo são: no canto superior direito 0 valor facial (cifra) "150,00", e no canto inferior esquerdo o nome do país emissor "Brasil", ao lado do ano de emissão "83". 0 destaque dado a esses elementos é obrigatório para todos os selos comemorativos, conforme normas internacionais estabelecidas nas sessões da União Postal Universal (UPU) $)^{3}$, do qual Brasil faz parte desde 1877.

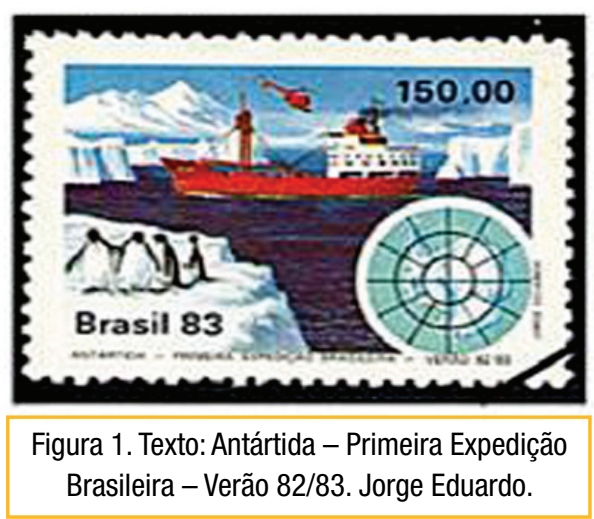

Um detalhe que pode ser observado nessa peça e que se repete em todos os demais selos da amostra é o fato de que esses três elementos obrigatórios sempre são impressos na parte interna da imagem. Cabe ao artista designado para elaborar o selo postal, baseado no denominado "Edital Filatélico", encontrar uma forma de incluir tudo o que especifica o Edital em paralelo ao seu ato criativo artístico.

Geralmente entre o limite do "quadro" e dos picotes são registrados o motivo da emissão

Essa participação brasileira foi fator decisivo para o desenvolvimento de seus serviços postais. A UPU é uma espécie de aliança de nações, ligadas a Organização das Nações Unidas (ONU), que tem por objetivo facilitar o intercâmbio internacional de missivas postais, regulando taxas e definindo responsabilidades e prioridades com relação ao serviço postal prestado no mundo inteiro. Segundo Almeida e Vasquez (2003, p. 68), "a UPU foi fundada em 1874, durante congresso realizado em Berna-Suiça, contando com 22 países signatários". Hoje ela é constituída por mais de 230 países e é responsável, com exclusividade, por toda a gestão de correspondências internas e externas da ONU.

0 Edital é um documento filatélico publicado no Diário Oficial da União, sancionado pelo Presidente da República ou pelo Ministro das Comunicações em que são especificados os textos a serem registrados, o motivo da emissão, as cores que serão utilizadas e a localização dos três elementos obrigatórios. 
da peça, sempre por meio de um enunciado, informações diversas como anos, nomes de pessoas ou lugares, nome do artista ou artistas designados para elaborar o artefato e, em certa medida, a sigla do órgão impressor do selo postal, a saber: Casa da Moeda do Brasil (CMB) ${ }^{5}$. Isso se repete na maioria dos selos da amostra analisada.

Excetuando a parte textual, que nesse caso específico fica fora dos limites da imagem principal, existem outros códigos icônicos ou pictóricos. Além dos icebergs, das montanhas cobertas de neve ao fundo, do oceano e do céu, tem-se em primeiro plano no canto inferior esquerdo, um grupo de quatro pinguins. Dois deles sugerem estar em movimento, pois estão com as asas afastadas do corpo além de ter umas das patas erguidas. Parecem estar afastandose da instabilidade ambiental causada pelo navio e pelo helicóptero, pelo medo que lhes foi proporcionado e em direção aos que os vêem na imagem, como que pedindo ajuda ou abrigo por não entenderem o que são essas máquinas, o que fazem ali, por que têm cores tão fortes ou motores tão barulhentos ou, por que entendem, de forma intuitiva, que as máquinas são predadoras.
No plano inferior direito há uma projeção cartográfica azimutal caracterizada pela projeção central dos meridianos à imagem central do mapa. Nesse caso o mapa inscrito é 0 continente Antártico. Esse tipo de representação corresponde à área científica denominada Cartografia. Observa-se uma pequena inadequação na representação, pois os meridianos (traços pretos) deveriam confluir até o ponto central do mapa, o que não ocorre. Essa imagem cartográfica indica a presença de uma iconicidade de caráter científico no selo. Talvez para enaltecer o sentido técnico-expedicionário da missão ou para tentar dissimular o caráter mais invasivo. Não é raro que a imagem científica tente silenciar os próprios malefícios que podem ser causados pelo uso inadequado do produto tecno-científico por ela mostrada.

Em segundo plano, observam-se, no centro da imagem, dois tipos de transportes utilizados pela expedição brasileira nas Operações Antárticas ${ }^{6}$. 0 navio de apoio oceanográfico Barão de Teffé (inutilizado) e um helicóptero do tipo "Esquilo", bi-turbinado, ambos adquiridos pela Marinha brasileira. 0 navio tinha capacidade para

Nem todos os selos brasileiros foram impressos pela Casa da Moeda do Brasil. Situações econômicas e políticas influenciam na decisão do lugar onde será impresso o selo postal ou outros documentos filatélicos, como ocorreu com a impressão de selos do final do Império e dos primeiros anos da República. Almeida e Vasquez (2003, p. 119) sugerem que, quando não foi possível a impressão na Casa da Moeda do Brasil, empresas como a "Tipografia Alexandre Ribeiro \& Cia ou a norte-americana American Bank Note Co" foram designadas para tal função.

Apenas em 1975 o Brasil decide aderir ao Tratado da Antártica - único diploma legal para o Continente Antártico, sendo instrumento jurídico válido e aceito para todos os membros que dele são parte - do qual passou a ser $019^{\circ}$ membro. Assim, com 0 objetivo de alcançar a condição de membro pleno, o Brasil elaborou o seu Programa Antártico (Proantar) em 1982. No mesmo ano, o navio de apoio oceanográfico Barão de Teffé e o navio oceanográfico Professor Wladimir Besnard, da Universidade de São Paulo, rumaram para a Antártica a fim de selecionar o local onde deveria ser instalada a futura estação brasileira. 
transportar dois helicópteros. A imagem só mostra um deles em ação.

Com o objetivo de dar início aos trabalhos de instalação da Estação Antártica Comandante Ferraz (EACF) e de possibilitar a admissão do Brasil ao Conselho Consultivo do Tratado da Antártica, o Brasil adquiriu o Navio de Apoio Oceanográfico (NApOc) Barão de Teffé, H-42, navio polar, com antigo nome de "Thala Dan". 0 navio participou de doze Operações Antárticas e serviu para fornecer apoio logístico e transporte de pessoal a EACF (SCHUCH, 2007).

As cores fortes, com tonalidades de vermelho ou laranja, são características desse tipo de transporte em terras geladas, por motivos de identificação e segurança. 0 navio parece estar em movimento ao considerar, tanto as ondas na parte dianteira do casco quanto a fumaça que sai da chaminé principal.

Tudo nessa imagem é movimento, ação. 0 andar ou correr dos pinguins, as ondas geladas do mar, 0 avanço do aposentado navio, o vôo de exploração e segurança do helicóptero, a fumaça que se espalha pelo puro ar antártico no sentido oposto ao sentido da embarcação e, por fim, um mapa que indica a localização geográfica da expedição.

Nesse selo postal comemorativo podem ser identificadas três áreas científicas: Biologia Marinha, Cartografia ou Geografia e Oceanografia. A imagem dos pinguins pode ser considerada como divulgação da fauna local. Por outro lado, remete ao estudo desse animal como resultado da expedição. Sendo assim, essa parte pictórica se encaixa na área da Biologia Marinha.
Do ponto de vista da Geografia, há um detalhe que remete ao termo "expedição", concernente ao escopo temático do selo postal, que constitui um conceito estudado numa subárea da Geografia denominado Geografia Cultural. 0 mapa azimutal remete inteiramente à Cartografia enquanto área científica. 0 conjunto dos elementos pode sugerir, a partir do próprio motivo da emissão do selo, 0 estudo oceanográfico.

0 continente Antártico, por sua vez, por ser um local distante, desconhecido, inóspito e praticamente inatingível para a maioria das pessoas, exerce um grande fascínio. A imagem do selo instiga e manifesta não apenas o imaginário sobre um lugar-espaço geográfico, mas também a presença da nação brasileira (político-científica), dos investimentos do Estado em tecnologias de transporte e da fauna local (pinguins).

0 que percebemos no exemplo de selo postal comemorativo que trouxemos para este artigo ocorre com dezenas de outros exemplares do corpus analisado. É por essa razão que defendemos que os selos postais podem ser considerados como pertencentes ao domínio discursivo dos meios de comunicação, contribuindo para dar visibilidade a objetos, a ações e a personalidades do mundo científico. Tomando o selo postal comemorativo como um dos meios de registro e de divulgação de informações de caráter científico, acreditamos na sua relevância para a construção de uma cultura científica. 


\section{Referências bibliográficas}

ALMEIDA, Cícero Almeida de; VASQUEZ, Pedro Karp. Selos postais do Brasil. São Paulo: Metalivros, 2003.

ALTMAN, Denis. Paper ambassadors: the politics of stamps. North Ryde: NSW, 1991.

BAKHTIN, Mikhail. Estética da criação verbal. 4. ed. São Paulo: Martins Fontes, 2003.

BERGER, John. Ways of seeing. London: Penguin, 1972, BESSIS, Henriette. A imagem da Ciência na pintura. In: VIERNE, Simone. A Ciência e o Imaginário. Brasília: UNB, 1994. p. 159 - 190.

BIRD, Jon et al (Ed.). The block reader in visual culture. New York: Routledge, 1996.

BRONOWSKI, Jacob. 0 olho visionário: ensaios sobre arte, literatura e ciência. Brasília: UNB, 1998.

BRYSON, Norman; HOLLY, Michael Ann; MOXEY, Keith (ed.). Visual theory: painting and interpretation. Cambridge: Polity, 1991.

Visual culture: images and interpretation.

London: Wesleyan University, 1994.

CATALOGO DE SELOS D0 BRASIL: 1843 - 2007. 56. ed. São Paulo: RHM, 2008.

CONTRERA, Malena Segura; BAITELLO Junior,

Norval. Na selva das imagens: algumas contribuições para uma teoria da imagem na esfera das ciências da comunicação. Significação. São Paulo, n. 25, jun. 2006, p. $113-126$.

DAMÁSIO, Antonio. 0 mistério da consciência. São Paulo: Cia. das Letras, 2000.

DIKOVITSKAYA, Margaret. Visual culture: the study of the visual after the cultural turn. London: MIT, 2005.

EDUARD0, Jorge. Antártida: primeira expedição brasileira 82/83. 1985. Selo postal, Color., 20mm x 54mm. (Coleção particular).
ELKINS, James. Visual Studies: essays on verbal and visual representation. New York: Routledge, 2003.

ELLUL, Jacques. A técnica e o desafio do século. São Paulo: Paz e Terra, 1968.

ERBOLATO, Mário de Lucca. Comunicação postal: propaganda, cultura e informação. Comunicarte, Campinas, v.1, n. 2, p. 111-123, 1983.

EVANS, Jessica; HALL, Stuart. (eds.). Visual culture: the reader. London: SAGE, 1999.

GRANGER, Gilles-Gaston. A Ciência e as Ciências. São Paulo: UNESP, 1994.

HASKELL, Francis. History and its images: art and the interpretation of the past. London: Yale University, 1993.

IZQUIERD0, Iván. Aumentando o conhecimento popular sobre a ciência. In: CONFERÊNCIA NACIONAL DE CIÊNCIA, TECNOLOGIA E INOVAÇÃO: desenvolvendo idéias para desenvolver o Brasil, 3, Brasília. Anais... Parcerias Estratégicas, Brasília, n. 20, parte 1, p. 113-118, jun. 2005.

JAY, Martin. Vision in context: reflections and refractions. In.: BRENNAN, Teresa; JAY, Martin (ed.).

Vision in context: historical and contemporary perspectives on sight. New York: Routledge, 1996.

KATZ, Cláudio. 0 enfoque marxista da mudança tecnológica. In: KATZ, Cláudio; COGGIOLA, Osvaldo. Neoliberalismo ou crise do capital? São Paulo: Xamã, 1996, p. 9 - 17.

KNAUSS, Paulo. 0 desafio de fazer História com imagens: arte e cultura visual. ArtCultura, Uberlândia, v. 8, n. 12, p. 97-115, jan - jun 2006.

MAFFESOLI, Michel. 0 eterno instante. Lisboa: Piaget, 2001.

MANGUEL, Aalberto. Lendo imagens. São Paulo: Cia. das Letras, 2003.

MENESES, Ulpiano Toledo Bezerra de. Fontes visuais, cultura visual, história visual: balanço provisório, 
propostas cautelares. Revista Brasileira de História. São Paulo, v. 23, n. 45, p. 11-36, jul. 2003.

MITCHELL, William John Thomas. Picture theory: essays on verbal and visual representation. Chicago: University, 1994.

MIRZOEFF, Nick. (Ed.). The visual culture reader. New York: Routledge, 1998.

PINHEIRO, Helano Diógenes; PINHEIRO, Daniel Rodriguez de Carvalho. Tecnologia e inovação nas sociedades capitalistas. Humanidades, Fortaleza, v. 17, n. 2, p. 157-160, ago. - dez. 2002.

SALCED0, Diego. Lacunas na Arquivologia contemporânea: uma perspectiva da Filatelia. Arquivstica.net, Rio de Janeiro, v. 2, n. 1, 2006. Disponível em: <http://www.arquivistica.net $>$. Acesso em 13.07.2008.

Filatelia e Memória: pequenos embaixadores de papel. In: VERRI, G. M. W. (org.). Registros do Passado no Presente. Recife: Bagaço, 2008. p. 155-195. SANTAELLA, Lúcia. A percepção: uma teoria semiótica. São Paulo: Experimento, 1993. .; NOTH, Winfried. A imagem: cognição, semiótica, mídia. 4. ed. São Paulo: Iluminuras, 2005.

SCHUCH, Luiz Alexandre. Conheça a Antártica: principais navios brasileiros. Santa Maria: UFSM, 2007. Disponível em: <http://www.ufsm.br/antartica> Acesso em: 16 abr. 2008.

SCHUMPETER, Joseph. A teoria do desenvolvimento econômico. 3. ed. São Paulo: Nova Cultura, 1988. 


\section{The visibility of science in} commemorative postal stamps

\section{Abstract}

This essay discusses how science is made public through postal stamps images. Science is part of a being-in-the-world notion, both in what is said and what is seen. Images have been used as a discursive resources which inform, communicate and question individuals, change their world and also play an important role in constructing social reality. Commemorative postal stamps may well be a way of communicating scientific informations, used both to send messages to the general public and to educate new readers of the world. Based on visual culture studies, we have searched to identify in a single postal stamp the presence of science in textual and pictorial levels.

\section{Keywords}

Commemorative postal stamp. Philately. Science communication. Visual culture.

\section{La visibilidad de la ciencia en sellos postales conmemorativos}

\section{Resumen}

Este artículo trata de la divulgación de la ciencia por medio de las imágenes impresas en los sellos postales. La ciencia hace parte cada vez más de la concepción de ser-en-el-mundo, tanto en los hechos como en los dichos y vistos. La imagen ha sido utilizada como un recurso discursivo que informa, comunica e interpela al individuo, modifica su mundo y tiene papel importante en la construcción de la realidad social. El sello postal, del tipo conmemorativo, puede ser considerado un medio de divulgación de las informaciones científicas utilizado tanto para enviar mensajes al grand público cuanto para educar nuevos lectores de mundo. Tomando por base estudios sobre culturas visuales, buscamos identificar en un sello postal la presencia da la ciencia en los niveles textual y pictórico.

\section{Palabras clave}

Cultura visual. Divulgación científica. Filatelia. Sello postal conmemorativo. 


\section{Expediente}

A revista E-Compós é a publicação científica em formato eletrônico da Associação Nacional dos Programas de Pós-Graduação em Comunicação (Compós). Lançada em 2004, tem como principal finalidade difundir a produção acadêmica de pesquisadores da área de Comunicação, inseridos em instituições do Brasil e do exterior.
E-COMPÓS I www.e-compos.org.br I E-ISSN 1808-2599

Revista da Associação Nacional dos Programas de Pós-Graduação em Comunicação. Brasília, v.12, n.1, jan./abr. 2009.

A identificação das edições, a partir de 2008 passa a ser volume anual com três números.

\section{CONSELHO EDITORIAL}

\section{Afonso Albuquerque}

Universidade Federal Fluminense, Brasil

Alberto Carlos Augusto Klein

Universidade Estadual de Londrina, Brasi

Alex Fernando Teixeira Primo

Universidade Federal do Rio Grande do Sul, Brasil

\section{Alfredo Vizeu}

Universidade Federal de Pernambuco, Brasil

Ana Carolina Damboriarena Escosteguy

Pontifícia Universidade Católica do Rio Grande do Sul, Bras

Ana Silvia Lopes Davi Médola

Universidade Estadual Paulista, Brasil

André Luiz Martins Lemos

Universidade Federal da Bahia, Brasil

Ângela Freire Prysthon

Universidade Federal de Pernambuco, Brasil

Antônio Fausto Neto

Universidade do Vale do Rio dos Sinos, Brasil

Antonio Carlos Hohlfeldt

Pontifícia Universidade Católica do Rio Grande do Sul, Brasil

Arlindo Ribeiro Machado

Universidade de São Paulo, Brasil

César Geraldo Guimarães

Universidade Federal de Minas Gerais, Brasil

Cristiane Freitas Gutfreind

Pontifícia Universidade Católica do Rio Grande do Sul, Brasil

Denilson Lopes

Universidade Federal do Rio de Janeiro, Brasil

Eduardo Peñuela Cañizal

Universidade Paulista, Brasi

Erick Felinto de Oliveira

Universidade do Estado do Rio de Janeiro, Brasil

Francisco Menezes Martins

Universidade Tuiuti do Paraná, Brasil

Gelson Santana

Universidade Anhembi/Morumbi, Brasi

Hector Ospina

Universidad de Manizales, Colômbia

leda Tucherman

Universidade Federal do Rio de Janeiro, Brasil

Itania Maria Mota Gomes

Universidade Federal da Bahia, Brasil

Janice Caiafa

Universidade Federal do Rio de Janeiro, Brasil

Jeder Silveira Janotti Junior

Universidade Federal da Bahia, Brasil

\section{João Freire Filho}

Universidade Federal do Rio de Janeiro, Brasil

John DH Downing

University of Texas at Austin, Estados Unidos

José Luiz Aidar Prado

Pontifícia Universidade Católica de São Paulo, Brasil

José Luiz Warren Jardim Gomes Braga

Universidade do Vale do Rio dos Sinos, Brasil

Juremir Machado da Silva

Pontifícia Universidade Católica do Rio Grande do Sul, Brasil

Lorraine Leu

University of Bristol, Grã-Bretanha

Luiz Claudio Martino

Universidade de Brasília, Brasil

Maria Immacolata Vassallo de Lopes

Universidade de São Paulo, Brasil

Maria Lucia Santaella

Pontifícia Universidade Católica de São Paulo, Brasil

Mauro Pereira Porto

Tulane University, Estados Unidos

Muniz Sodre de Araujo Cabral

Universidade Federal do Rio de Janeiro, Brasil

Nilda Aparecida Jacks

Universidade Federal do Rio Grande do Sul, Brasil

Paulo Roberto Gibaldi Vaz

Universidade Federal do Rio de Janeiro, Brasil

Renato Cordeiro Gomes

Pontifícia Universidade Católica do Rio de Janeiro, Brasil

Ronaldo George Hela

Universidade do Estado do Rio de Janeiro, Brasil

Rosana de Lima Soares

Universidade de São Paulo, Brasil

Rossana Reguillo

Instituto Tecnológico y de Estudios Superiores do Occidente, México

Rousiley Celi Moreira Maia

Universidade Federal de Minas Gerais, Brasil

Sebastião Carlos de Morais Squirra

Universidade Metodista de São Paulo, Brasi

Simone Maria Andrade Pereira de Sá

Universidade Federal Fluminense, Brasil

Suzete Venturelli

Universidade de Brasília, Brasil

Valério Cruz Brittos

Universidade do Vale do Rio dos Sinos, Brasil

Veneza Mayora Ronsini

Universidade Federal de Santa Maria, Brasil

Vera Regina Veiga França

Universidade Federal de Minas Gerais, Brasil
COMISSÃO EDITORIAL

Ana Gruszynski I Universidade Federal do Rio Grande do Sul, Brasil

Rose Melo Rocha I Escola Superior de Propaganda e Marketing, Brasil

CONSULTORES AD HOC

Alberto Schneider I Visitante Tokyo University

Alexandre Rocha da Silva I Universidade Federal do Rio Grande do Sul, Brasil

Fernanda Bruno I Universidade Federal do Rio de Janeiro, Brasil

Ida Stumpf I Universidade Federal do Rio Grande do Sul, Brasil

Kati Caetano I Universidade Tuiuti do Paraná, Brasil

Laura Cánepa I Universidade Anhembi Morumbi, Brasi

Malena Contrera I Universidade Paulista, Brasil

Sandra Gonçalves I Universidade Federal do Rio Grande do Sul, Brasil

Vicente Gosciola I Universidade Anhembi Morumbi, Brasil

REVISÃO DE TEXTO E TRADUÇÃo I Everton Cardoso

EDITORAÇ̃̃o ELETRÔNICA I Raquel Castedo
COMPós I www.compos.org.br

Associação Nacional dos Programas de Pós-Graduação em Comunicação

Presidente

Erick Felinto de Oliveira

Universidade do Estado do Rio de Janeiro, Brasil erickfelinto@uol.com.br

Vice-presidente

Ana Silvia Lopes Davi Médola

Universidade Estadual Paulista, Brasil

asilvia@faac.unesp.br

Secretária-Geral

Denize Correa Araújo

Universidade Tuiuti do Paraná, Brasil

denizearaujo@hotmail.com 